\title{
ANALISIS KRITIS TEORI DAN PENERAPAN KONSEP KHILAFAH PASCA NABI SAW WAFAT
}

\author{
Abdurrahman Abdullah \\ abdrahmanabdullah@gmail.com
}

\begin{abstract}
Abstrak
Penelitian ini mengungkap beberapa fakta-fakta sejarah yang terjadi dalam suksesi kepemimpinan pasca Nabi SAW wafat, serta berbagai peristiwa yang menyertainya yang tak jarang diwarnai kemelut dan bibit perpecahan di tubuh umat Islam. Selain itu, akan dianalisis mengenai ragam konsep khilafah dalam khazanah filsafat Politik Islam, yang menunjukkan bahwa konsep khilafah selalu mengalami pergeseran dan persinggungan, baik konsep maupun penerapannya. Sehingga secara general dapat diasumsikan bahwa tidak ada konsep khilafah yang baku dan mutlak untuk diklaim oleh sebagai golongan dalam perjalanan sejarah Islam. Maka penting umat Islam utuk mengelaborasi secara terus-menerus mengenai konsep khilafah, yang boleh jadi, sangat berbeda penerapannya di setiap zaman. Utuk menelisik hal tersebut lebih mendalam maka dalam tulisan ini diajukan dua rumusan masalah yakni Bagaimana perkembangan penerapan konsep khilafah di dunia Islam pasca Nabi Saw Wafat, dan Bagaimana perkembangan teori mengenai khilafah menurut para ulama, yang dianalisis menggunakan metode kualitatif deskriftif.
\end{abstract}

Kata Kunci: Analisis Kritis, Konsep, Khilafah

\section{A. Pendahuluan}

Kepemimpinan di dunia Islam setelah Nabi Saw wafat adalah masalah pelik. Sangat banyak varian pemikiran dan berbagai hal yang mewarnai panggung sejarah dari sejak penerapan konsep kepemimpinan model kekhilafahan, yaitu pada masa Abu Bakar ibn Abi Quhafah hingga khilafah Ali Ibn Abi Thalib serta intrik politik semakin tajam pada masa khilafah Hasan Ibn Ali. Hal tersebut lebih disebabkan, menurut penelusuran dari berbagai kitab tarikh dan hadits-hadits shahih di kalangan Ahlus Sunnah, Nabi Saw tidak pernah mewasiatkan masalah kepemimpinan. 
Pada hari Kamis, empat hari menjelang Nabi Saw wafat, seperti diceritakan oleh Ibn Abbas, Nabi memberikan wasiatnya untuk umat, yang disebutkan oleh Nabi niscaya umat Islam tidak akan tersesat setelahnya. Kisah hari Kamis ini dikutip dalam banyak kitab Tarikh terkemuka, seperti dalam Tarikh Thabari (Vol.III, t.t.:192-193), Tarikh Ibn Atsir (Vol.II, t.t.:183), dan Tarikh Ibn Khaldun (Vol.II, 2000:485). Kisah ini juga termuat di kitab-kitab Hadits Shahih, seperti di Kitab Shahih Bukhari (Kitab Jizyah, Vol.IV:66) di beberapa bab dan di Kitab Shahih Muslim (Kitab alWashiyyah, hal.1637).

Diceritakan dari riwayat Ibn Abbas, bahwa Nabi menjelang wafatnya dalam keadaan sakit bersabda, "Berikan saya kertas dan pena, akan kutulis buat kalian tulisan yang niscaya kalian tidak akan tersesat setelahku." Para sahabat yang hadir ramai berselisih, ada yang berkata, "Nabi sedang mengigau dikarenakan sakit yang luar biasa". Nabi Saw marah seraya berkata, "Sesungguhnya aku dalam kondisi yang lebih baik dari apa yang kalian kira". Disebutkan bahwa Nabi kemudian mewasiatkan tiga hal: (1) agar mengeluarkan kaum musyrikin dari jazirah Arab, (2) memperlakukan dengan baik para utusan sebagaimana Nabi Saw selalu memperlakukannya, dan yang ketiga Nabi diam, atau disebutkan di banyak kitab tarikh dan hadits, perawinya lupa atas apa wasiat Nabi yang ketiga.

Setelah Nabi Saw wafat, dua tokoh kunci yang dipandang layak menggantikan posisi Nabi Saw saat itu bermuara pada dua orang shahabat, yaitu apakah Abu Bakar ibn Abi Quhafah ataukah Ali ibn Abi Thalib (Ibn Atsir, 2012:187; Ath-Thabari, Vol.III, t.t,:202). Meskipun, pada saat terjadi suksesi kepempinan tepat setelah Nabi Saw wafat, Ali ibn Abi Thalib lebih bersikap pasif, karena sedang fokus mengurusi pemakaman jenazah sang Rasul tercinta (Ibn Atsir, Vol.II, 2012:193). Sementara Abu Bakar sangat agresif dengan didukung penuh oleh "tim sukses" utamanya, yaitu Umar ibn Khattab dan Abu 'Ubaidah ibn Jarrah (Abi Syaibah, Vol.II, t.t.:432).

Abu Bakar akhirnya terpilih menjadi Khalifah pertama mewakili golongan Muhajirin setelah diba'iat di forum pertemuan antara kalangan Anshar dan Muhajirin (meskipun Muhajirin hanya diwakili oleh tiga orang) di rumah Saqifah Bani Sa'idah.

Peristiwa Saqifah dan rangkaian peristiwa setelahnya merupakan peristiwa penting dalam sejarah Islam sebagai bahan bagaimana kita bisa 
melihat secara jernih permasalahan pengisian kekuasaan atau suksesi kepemimpinan pasca Nabi Saw wafat. Bahkan, suksesi kepemimpinan pada masa Umar hingga periode khilafah Hasan Ibn Ali selalu dinamis, konsepnya pun berubah-ubah. Abu Bakar naik menjadi khalifah dengan sistem demokrasi terbatas yaitu terpilih secara musyawarah di rumah Saqifah Bani Sa'idah, Umar Ibn Khattab terpilih melalui sistem penunjukan langsung dengan surat wasiat dari khalifah sebelumnya. Berbeda dengan Utsman ibn Affan yang terpilih melalui sistem $\mathrm{Ahl}$ al-Hal wal 'Aqd, begitu pun Ali ibn Abi Thalib berbeda pula sistem yang digunakan oleh umat Islam saat itu, yaitu dengan sistem pemilihan langsung oleh umat Islam.

\section{B. Perumusan Masalah}

Bahasan pokok dalam penelitian ini akan memfokuskan pembahasan pada beberapa pokok permasalahan sebagai berikut:

1. Bagaimana perkembangan penerapan konsep khilafah di dunia Islam pasca Nabi Saw Wafat?

2. Bagaimana perkembangan teori mengenai khilafah menurut para ulama?

\section{Metode Penelitian}

Penelitian menggunakan pendekatan kualitatif deskriftif yakni metode yang berusaha mengalisi data-data primer berupa teks, dokumen tulisan lain yang relevan dengan metode pengumpulan data sekunder dari buku-buku primer (Jhony. 35) seperti Tarikh yang ditulis oleh para penulis sejarah Islam terkemuka, seperti Kitab Tarikh Ibn Qutaibah, Kitab Tarikh Ibn Atsir, Tarikh Ibn Khaldun, Tarikh as-Suyuthi, Tarikh ath-Thabari, Tarikh Ibn Hisyam, Tarikh al-Ya'qubi, dan sumber penunjang lain.

\section{Pembahasan}

\section{Penerapan Konsep Khilafah}

Suksesi kepemimpinan Abu Bakar terjadi di rumah Saqifah Bani Sa'idah. Peristiwa ini tercatat di banyak kitab tarikh terkemuka. Ibn Qutaibah (Vol.I, 1990:24), Jalaluddin As-Suyuthi (t.t.:60-62) dan Ibn Atsir (Vol.II, 2012:189-195) menuliskan bab khusus dengan sangat rinci mengenai peristiwa di Saqifah. Begitu pun Ath-Thabari (Vol.III, t.t.:203206). Para ulama tarikh lain seperti Al-Ya'qubi, Ibn Hisyam dan Ibn Khaldun (Vol.II, t.t.:487) pun sama-sama mencatat hal tersebut. Imam 
Ahmad ibn Hanbal dalam Musnad-nya pun mengutip hadits yang panjang mengenai peristiwa Saqifah ini (hadits ke-532).

Disebutkan bahwa, setelah Nabi Saw wafat para pembesar Anshar berkumpul di rumah Saqifah Bani Saidah, yang di antaranya diinisiasi oleh Sa'ad bin Ubadah (pemimpin suku Khazraj). Sa'ad bin Ubadah yang waktu itu sedang sakit tidak mampu berbicara banyak dan meminta kepada anaknya untuk menyampaikan apa yang ia ingin sampaikan kepada para kaum Anshar yang berkumpul di tempat itu. Sa'ad menyampaikan mengenai keunggulan kaum Anshar atas kelompok-kelompok muslim lainnya, yaitu mereka yang telah melakukan pelayanan kepada Islam dan Nabi Muhammad saw dan ketika Nabi wafat, beliau merasa puas dengan kelompok Anshar. Dengan alasan-alasan ini Sa'ad hendak meyakinkan bahwa kaum Anshar lebih utama untuk menggantikan kedudukan dalam mengatur seluruh urusan umat Islam sepeninggal Nabi Saw (Ath-Thabari, Vol.III:203-206; Ibn Khaldun, Vol.II:487).

Kabar mengenai berkumpulnya kaum Anshar di Saqifah ini kemudian sampai kepada Umar bin Khattab dan Abu Bakar. Dengan tergesa-gesa keduanya segera pergi ke Saqifah dan di tengah jalan berjumpa dengan Abu 'Ubaidah ibn Jarrah, ketiganya pun lantas bersamasama menghampiri Kaum Anshar (Ibn Atsir, 2012:189- 195.

Sesampainya di Saqifah, juru bicara kaum Anshar berkata, "Kami, kaum Anshar, adalah bersatunya pasukan Islam, dan kalian, wahai kaum Quraisy, adalah sekelompok kecil dari kami dan minoritas dari kami" (AsSuyuthi, 1990:61).

Umar ibn Khattab bermaksud menanggapi, tetapi Abu Bakar mencegah dan dia sendiri berkata, "Apapun yang kau katakan tentang kaum Anshar memang benar, tetapi bangsa Arab tidak mengakui khilafah kecuali untuk suku Quraisy. Mereka adalah yang terbaik dari bangsa Arab dari sisi keturunan. "Kami dari suku Quraisy dan para Imam haruslah dari kami. Di antara kalian saat ini ada dua orang dari Quraisy, yaitu Abu 'Ubaidah dan Umar ibn Khattab, pilihlah salah satu dari mereka berdua", ujar Abu Bakar. Namun kemudian dijawab oleh Umar, bahwa Abu Bakar lebih berhak daripada dirinya. Abu Bakar, menurut Umar, adalah shahabat terbaik dari kalangan Muhajirin (Ibn Qutaibah, Vol.I, t.t.:26; Ibn Khaldun, Vol.II, t.t.:487).

Hubbab al-Mundzir, salah seorang tokoh Anshar berkata dengan nada keras, "Biarkan ada seorang pemimpin dari kami dan seorang lagi 
dari kalian". Umar ibn Khattab menjawab, "Dua pedang tak bisa ditempatkan dalam satu sarung" (As-Suyuthi, t.t.:61).

Suasana berubah menjadi kacau, suara-suara tinggi dari banyak orang saling menimpali. Lalu Umar meminta tangan Abu Bakar dan mengangkatnya serta bersumpah setia seraya berkata, "Kaum Muhajirin dan Anshar berba'iat kepadanya." Basyir bin Sa'ad dan Usaid bin Hudhair (bangsawan suku Aus Madinah) bangkit dan bersumpah setia dan banyak yang mengikutinya.

Sa'ad bin 'Ubadah menolak untuk berbai'at pada Abu Bakar dan nyaris terbunuh di saat kebanyakan kaum Anshar yang hadir pada saat itu berebut membaiat Abu Bakar, khususnya dari kalangan Anshar suku Aus. Kaum Anshar menyampaikan kekhawatirannya jangan sampai Sa'ad ibn Ubadah terbunuh, namun Umar ibn Khattab mengatakan, "Semoga Allah membunuhnya" (Ibn Khaldun, Vol.II, t.t.:487-488).

Sa'ad bin Ubadah sampai akhir hayatnya tidak membaiat Abu Bakar. Ketika Abu Bakar wafat dan digantikan oleh Umar ibn Khattab, Sa'ad pun tidak mau membaiat Umar (Ibn Qutaibah, t.t.:203-204). Selain Sa'ad, Hubbab ibn Mundzir pun menentang baiat kaum Anshar terhadap Abu Bakar. Hubbab mencabut pedang dari sarungnya ketika ia melihat kaum Anshar bersumpah setia pada Abu Bakar, namun mereka melucuti pedangnya. Hubbab berkata kepada kaum Anshar, "Kalian harus menunggu dan menyaksikan anak-anak kalian mengemis demi semangkuk air dan sepotong roti di depan pintu kaum Quraisy" (Ibn Atsir, Vol.II, 2012:189-195). Umar lalu menghardik Hubbab, "Semoga Allah membunuhmu", dan dijawab oleh Hubbab ibn Mundzir, "Tidak, melainkan semoga Allah membunuhmu” (Ibn Atsir, Vol.II, 2012:191).

Keterpilihan Abu Bakar di Saqifah Bani Saidah diakui oleh Umar bin Khattab pada suatu khutbah Jum'at di Madinah sebagai suatu hal yang faltah (ketergesa-gesaan), namun menurut Umar, Allah Swt telah melindungi dari dampak buruknya (Ibn Hisyam, Vol.IV, t.t.:309).

Di sumber yang lain disebutkan bahwa keterpilihan Abu Bakar disebut dengan kalimat kafalatatin jahiliyyah (ketergesa-gesaan seperti di abad jahiliyyah), di mana dalam prosesnya terjadi huru-hara yang melibatkan kemelut sengit antara Muhajirin dan Anshar, di antaranya pertengkaran yang dahsyat antara Umar ibn Khattab dengan Hubbab ibn Mundzir dengan dipatahkannya pedang Hubbab oleh Umar sambil 
memukul tangan Hubbab, serta peristiwa terinjak-injaknya Sa'ad ibn 'Ubadah dan celaan Umar terhadap Sa'ad yang menyebutnya dengan sebutan munafik (Ath-Thabari, Vol.III, t.t.:223), dan hampir terbunuh karena perintah Umar untuk membunuhnya di forum tersebut namun diredam oleh Abu Bakar (Ibn Khaldun, Vol.III, 2000:488).

Abu Bakar lalu menjadi khalifah dan menyampaikan khutbahnya di hadapan kaum muslimin, "Aku mengambil alih kepemimpinan atas kalian, sedangkan aku tidak lebih baik dari kalian. Jika aku bersikap baik, bantulah aku. Jika tidak, bimbinglah aku. Taatilah aku selama aku taat kepada Allah, jika tidak kalian tidak perlu menaatiku" (Ibn Hisyam, Vol.IV, 1990:312; Ath-Thabari, Vol.III, t.t.:200).

Pasca peristiwa di Saqifah, shahabat Nabi Saw terbelah menjadi dua kubu, yaitu yang menerima Abu Bakar sebagai khalifah dan kubu yang menolak. Kubu shahabat yang menerima adalah sebagian kaum Anshar dan para shahabat Muhajirin di antaranya Umar ibn Khattab, Abu 'Ubaidah ibn Jarrah, Mughirah ibn Syu'bah dan Khalid ibn Walid (Ath-Thabari, Vol.III, t.t.:202). Adapun kubu shahabat yang menolak adalah sebagian kaum Anshar dan sebagian shahabat dari kalangan Muhajirin seperti Zubair ibn Awwam, Khalid ibn Sa'id, Miqdad ibn Amr, Salman al-Farisi, Abu Dzar alGhifari, 'Ammar, Bara' bin Azib, dan Ubay ibn Ka'ab (Al-Ya'qubi, Vol.II, 2010:124).

Keluarga Nabi Saw, termasuk Ali ibn Abi Thalib dan 'Abbas, tidak berba'iat kepada Abu Bakar (Ath-Thabari, Vol.III, t.t.:203). Begitu pula dengan Puteri Nabi Saw, Fathimah az-Zahra, yang oleh Nabi Saw dalam hadits yang diriwayatkan dalam Kitab Shahih Bukhari disebutkan bahwa "Fathimah adalah bagian dari diriku, barangsiapa membuatnya murka berarti murkaku", tidak merestui Abu Bakar sebagai khalifah (Shahih Bukhari, Bab Fadhail Fathimah, hadits No.61).

Para shahabat pendukung Abu Bakar mendatangi rumah Ubay ibn Ka'ab untuk meminta sumpah setia pada khalifah Abu Bakar, namun Ubay tidak membukakan pintu bagi mereka. Kemudian mereka mendatangi rumah Ali ibn Abi Thalib ketika di rumah tersebut sedang berkumpul beberapa orang shahabat. Mereka mendapat perlakuan keras dari Umar yang berniat untuk meminta bai'at kepada Abu Bakar. Umar mengancam penghuni rumah bahwa ia akan membakar rumah itu. Ketika Umar diingatkan, bahwa di rumah itu ada Fathimah, puteri Rasulullah saw 
tercinta, Umar mengatakan, "meskipun ada Fathimah di dalamnya" (AthThabari, Vol.III, t.t.:202).

Fathimah hingga akhir hidupnya tidak pernah berbaiat kepada Abu Bakar. Ali ibn Abi Thalib dan para shahabat lainnya kemudian mau berba'iat kepada Abu Bakar setelah Fathimah wafat, yaitu enam bulan setelah Nabi Saw meninggal dunia (Ibn Atsir, 2012:192).

Selain itu, bermunculan para kelompok kaum Muslimin yang melakukan tindakan yang di antaranya enggan membayar zakat. Terhadap golongan yang membangkang ini, Abu Bakar ibn Abi Quhafah memerintahkan untuk memerangi kelompok pembangkang zakat (AsSuyuthi, 2013:66-67). Artinya, peperangan pertama era pemberlakuan khilafah adalah peperangan yang terjadi di antara kaum Muslim sendiri karena adanya perbedaan pandangan tentang penerapan khilafah.

Dalam kitab Tarikh ath-Thabari dikatakan bahwa alasan kelompok yang tidak mau membayar zakat adalah dikarenakan semasa Nabi Saw hidup, mereka menyerahkan zakat kepada Nabi sebagai pengakuan kepemimpinan Nabi. Adapun sepeninggal Nabi, mereka tidak mengakui kepemimpinan Abu Bakar dan tidak mau menyerahkan zakat kepadanya. Bahkan, kaum Anshar atau sebagian dari Anshar, pada saat peristiwa di Saqifah awalnya bersikukuh untuk tidak berbaiat kepada Abu Bakar. Mereka mengatakan secara tegas: "Kami tidak akan berbaiat kecuali kepada Ali Ibn Abi Thalib" (Ath-Thabari, Vol.III, t.t.:242-244).

Sejarah terus berjalan, khilafah dari masa ke masa memang memiliki dampak positif di antaranya wilayah Islam semakin meluas, perkembangan ilmu dan peradaban, serta munculnya banyak para pemikir dari kalangan Muslim pada era kekhalifahan yang hasil karyanya banyak diadopsi oleh para pemikir modern. Namun, penerapan sistem kekhalifahan juga banyak diwarnai pembantaian nyawa manusia, baik yang berbeda agama atas dasar motif ekspansi wilayah kekuasaan maupun atas dasar motif penumpasan kelompok-kelompok yang berbeda dengan kemauan khalifah yang berkuasa. Kelompok-kelompok yang ditumpas tersebut kebanyakan dari kalangan Muslim sendiri.

Asy-Syahrastani (t.t.:299) dalam Kitab Al-Milal wa an-Nihal menyebutkan mengenai pertumpahan darah dalam perebutan kekuasaan dalam Islam dengan ungkapan, "Tidak pernah suatu pedang terhunus 
dalam Islam atas dasar prinsip agama seperti terhunusnya pedang atas dasar kepemimpinan (al-imamah) pada setiap zaman".

Khalid ibn Walid diceritakan di banyak kitab tarikh pernah membunuh kaum yang dituduh murtad pimpinan Malik ibn An-Nuwairah lalu mengawini paksa Ummu Tamim, istri Malik, pada hari yang sama. Perbuatan Khalid ibn Walid, yang sering dijuluki Saifullah (Sang Pedang Allah) itu, dibenci oleh Umar ibn Khattab dan bahkan mengusulkan kepada khalifah Abu Bakar agar Khalid dibunuh karena telah membunuh kaum Muslim serta dirajam karena telah berbuat zina. Namun Abu Bakar menolaknya dengan alasan Khalid berta'wil (inisiatif atau ijtihad) namun salah (Ibn Atsir, 2012:217).

Pembunuhan juga terjadi terhadap para khalifah. Khalifah Umar ibn Khattab, Utsman ibn Affan, dan Ali ibn Abi Thalib, ketiganya dibunuh oleh kaum Muslim sendiri. Begitu pun dengan banyak khalifah-khalifah lain di zaman Umawiyyah, Abbasiyah, dan dinasi-dinasti setelahnya. Kenyataankenyataan ini adalah fakta sejarah yang terekam rapi oleh banyak ahli. Belum lagi jika bercerita tentang kepedihan para keluarga Nabi Saw yang mayoritas selalu diburu dan dibunuh oleh para penguasa pada zamannya. Ketika masa pemerintahan Yazid ibn Mu'awiyah, Jalaluddin as-Suyuthi (2012:184) menceritakan peristiwa sadis yang menimpa cucu Rasulullah Saw, Husain ibn Ali. As-Suyuthi bahkan banyak menyebutkan bahasabahasa kiasan karena ketidaktegaannya menyebutkan kepedihan atas pembantaian keluarga Nabi Saw tersebut.

Fakta-fakta ini menjadi satu modal untuk menganalisis: apakah memang kekhalifahan sebagai satu sistem kepemimpinan dalam Islam mensyaratkan adanya pertumpahan darah, perebutan kekuasaan dengan kekerasan, tindakan keji, ataukah memang ada penyimpangan dalam penerapan konsep khilafah dalam sejarah. Pertanyaan lain yang layak diajukan adalah, jika melihat konteks penerapan khilafah hingga kemudian sistem khilfah tumbang setelah era Turki Utsmani dan tidak ada lagi negara yang menerapkannya, apakah hal itu berarti sistem khilafah merupakan bukan sebagai kewajiban yang harus ditegakkan. Pertanyaanpertanyaan ini penting untuk dijawab sebagai acuan dan pedoman untuk merumuskan pergerakan Islam di masa kini dan masa depan.

\section{Ragam Teori tentang Khilafah}

Menarik untuk dikaji mengenai berbagai hal yang berkaitan dengan konsep khilafah, seperti sistem khilafah yang bagaimana yang dianjurkan 
dalam ajaran Islam, ada-tidaknya contoh baku bentuk pemerintahan dalam Islam, bagaimana konteks penerapan sistem khilafah pada era sekarang, serta berbagai tema lainnya.

Para ulama sepakat bahwa secara fitrah, jika terdapat manusia lebih dari satu orang dalam suatu tempat, maka ia membutuhkan pemimpin di antara mereka untuk menggapai tujuan dari orang-orang tersebut (Najar, t.t.:3). Itu pula sebabnya kenapa Islam mengatur serius akan hal ini. Islam mewajibkan untuk mengangkat pemimpin, khalifah, imam, amir, atau sebutan lainnya.

Nabi Muhammad saw pernah bersabda: "Jika ada tiga orang bepergian, hendaknya mereka mengangkat salah seorang di antara mereka menjadi pemimpinnya." (HR Abu Dawud)

Hadits ini memberikan gambaran yang cukup jelas bahwa perkara mengenai mengangkat pemimpin adalah perkara yang serius. Betapa untuk urusan yang sederhana pun (bepergian), Nabi Saw menyuruh untuk mengangkat pemimpin, apalagi untuk urusan yang punya kepentingan dan skala prioritas yang jauh lebih besar.

Namun begitu, mayoritas pendapat ulama berpendapat bahwa sifat wajib untuk mengangkat atau memilih pemimpin ini tidak serta merta berlaku untuk memilih sistem pemerintahan atau sistem kepemimpinan. Sebab ada perbedaan yang mendasar. Al-Quran dan Hadits hanya merinci dengan jelas perihal kewajiban mengangkat pemimpin, sedangkan untuk proses pemilihan pemimpin dan mekanisme kepemimpinan, Al-Quran dan Hadits tidak memerinci dengan detail.

Ditambah lagi, fakta-fakta sejarah membuktikan bahwa konsep tentang khilafah ini terus dinamis. Selalu berbeda-beda penerapannya. Penerapan dalam sejarah yang berbeda, dengan sendirinya membawa pada perubahan konsep yang mewarnai perubahan itu. Sebagai contoh, Abu Bakar terpilih menjadi khalifah pertama dengan sistem musyawarah antara kelompok Muhajirin dan Anshar (Ibn Hisyam, 1990:308-309). Meskipun, secara keterwakilan kelompok Muhajirin sangat tidak terwakili. Kelompok Muhajirin yang hadir pada forum yang diadakan di rumah Saqifah bani Saidah hanya dihadiri oleh tiga orang, yaitu Abu Bakar, Umar ibn Khattab dan Abu 'Ubaidah (Ibn Atsir, 2012:218).

Berbeda dengan sistem pengangkatan khalifah Umar yang terpilih dengan sistem penunjukan langsung dari Abu Bakar ibn Abi Quhafah (Ath- 
Thabari, t.t.:428). Perubahan sistem penunjukan pada era ini, seperti diutarakan oleh Rasyid Ridha (t.t.:10), mengilhami terbentuknya sistem pemerintahan monarkhi pada era Umawiyyah dan setelahnya, di mana pengangkatan khalifah dilakukan dengan penunjukan langsung oleh khalifah yang menjabat kepada orang yang dikehendakinya, yang kebanyakan dari kalangan keluarga atau kerabat.

Berbeda pula dengan pengangkatan khalifah Utsman ibn Affan yang terpilih melalui sistem musyawarah, atau yang sering disebut dengan sistem ahl al-hal wa al-'aqd. Khalifah Umar membentuk formatur atau dewan syura yang terdiri dari enam orang shahabat, yaitu Utsman bin Affan, Ali bin Abi Thalib, Thalhah bin Ubaidillah, Zubair bin Awwam, Sa'ad bin Abi Waqqash, dan Abdurrahman bin Auf Umar memberikan tanggung jawab (ketua) atas pemilihan ini kepada Abdurrahman bin Auf untuk memilih salah satu di antara keenam orang ini.

Berbeda lagi dengan pengangkatan khalifah Ali ibn Abi Thalib yang terpilih bukan dengan ketiga cara sebagaimana dilakukan oleh para khalifah pendahulunya. Ia diba'iat secara langsung oleh umat Islam yang memintanya untuk memimpin umat untuk mengakhiri berbagai kemelut dan kerusuhan yang hampir merebak setelah wafatnya Utsman ibn Affan. Hasan ibn Ali menjadi khalifah setelah ayahnya syahid, hampir sama yaitu atas permintaan dari umat Islam.

Perbedaan dalam sistem pengangkatan khalifah dari rekam jejak sejarah ini, pada gilirannya, melahirkan dualisme konsep tentang hal tersebut. Di kutub yang satu bahwa pengangkatan khalifah dilakukan melalui sistem musyawarah, sedangkan di kutub lain, pengangkatan khalifah dilakukan dengan sistem penunjukan langsung. Yang manakah sebenarnya sistem Islam hakiki yang harus diterapkan? Ini menjadi pertanyaan besar. Ataukah, cara pandang yang harus dipahami oleh umat Islam masa sekarang bahwa kedua sistem tersebut merupakan hal yang fleksibel yang dapat disesuaikan dengan konteks zaman. Ini pun menjadi pertanyaan yang harus dicari jawabannya, baik dari aspek naqli maupun aqli.

Permasalahan sistem khalifah juga terjadi pada konsep mengenai syarat atau karakteristik dari pemimpin (khalifah). Tidak ada bukti sejarah yang dapat menyebutkan bahwa terdapat syarat pemimpin baku yang pernah dijadikan rujukan oleh umat Islam yang secara ketat dipatuhi. Keterpilihan pemimpin banyak dipengaruhi oleh kultur dominasi suku dan 
aspek politis yang terjadi pada masanya. Hal ini lebih menguat dengan ditunjang oleh hadits mengenai keutamaan suku Quraisy dibandingkan dengan suku lain. Namun, hadits ini pun ternyata tidak diterapkan secara konsisten di banyak periode daulah-daulah Islam seperti pada era dinasti Ayyubiyah dan dinasti Bani Saljuk, bahkan pada zaman daulah Umawiyyah, daulah Abbasiyah, serta pada zaman Khulafaur Rasyidin sekalipun.

Karena ketiadaan syarat-syarat utama dari seorang khalifah, sejarah banyak mencatat mengenai sosok pemimpin yang malah tidak sesuai dengan nilai-nilai Islam. Pernah suatu masa, Khilafah Islam dipimpin oleh khalifah Al-Walid bin Yazid bin Abdul Malik. As-Suyuthi (1990:223) dalam kitab Tarikh al-Khulafa menyebutnya sebagai khalifah fasik, pemabuk, bahkan ia minum khamar di atas Ka'bah, pengidap homoseksual dan perbuatan keji lainnya. Dari sumber lain disebutkan ia pernah memanah alQuran dan menantang kekuasaan Allah. Thabari berkata mengenai khalifah Walid, "Ada banyak riwayat mengenai penghinaan Walid terhadap agama". Ath-Thabari (Vol.V, t.t.:538) tidak menyebutkan kebanyakan dari perbuatan Walid agar tidak memubadzirkan kata.

Pernah juga khilafah Islam dipimpin oleh Hisyam bin Abdul Malik. Ia melakukan pembunuhan sadis terhadap keturunan Nabi Saw, yaitu pada Zaid ibn Ali ibn Husain. Ia memerintahkan untuk membunuh Zaid. Zaid terbunuh dengan dipanah di keningnya. Kepalanya dipancung. Kuburannya disembunyikan, tetapi kemudian disuruh digali dan mayat Zaid digantung dan disalib serta tidak diturunkan selama berbulan-bulan. Setelah Hisyam turun tahta baru diturunkan, tetapi mayatnya dibakar dan abunya dibuang ke sungai Eufrat (Kan'an, 2013:143).

Dari banyaknya fakta sejarah mengenai khalifah yang tidak sesuai dengan nilai-nilai Islam inilah, tidak berlebihan jika Imam Syafii hanya mengakui kekhalifahan pada lima khalifah, yaitu empat orang dari Khulafa ar-Rasyidin dan khalifah Umar ibn Abdul Aziz (Ar-Razi, 1424 H:189).

Berbeda dengan penuturan Jalaluddin As-Suyuthi yang menyebut bahwa jumlah khalifah ada 12 yaitu: empat orang dari Khulafa ar-Rasyidin, Hasan ibn Ali, lalu dari Daulah Umawiyyah mengakui Muawiyah, Ibn Zubair, dan Umar ibn Abdul Aziz. Itu berarti berjumlah delapan. Ditambah Al-Muhtadi dari Bani Abbas karena sifatnya seperti Umar ibn Abdul Aziz dan terakhir Adh-Dhahir. Berarti berjumlah sepuluh orang. Dua orang lagi, menurut As-Suyuthi (1990:16), adalah dua orang yang dinantikan (A/- 
Muntadlaran), salah satunya yaitu Al-Mahdi karena dia dari keluarga Nabi Saw. Jalaluddin As-Suyuthi, hanya menyebutkan 11 orang dari 12 orang jumlah khalifah. Satu orang lagi tidak disebutkan olehnya. Pernyataan AsSuyuthi ini menambah deretan panjang bukti sejarah dari premis bahwa tidak ada konsep baku dan tetap yang dipatuhi secara ketat dalam sejarah panjang kekhalifahan umat Islam.

Dalam sistem pemerintahan, konsep khilafah mengalami perubahan yang berbeda coraknya dari masa ke masa. Bentuk pemerintahan di Madinah seperti dipraktekkan oleh Khulafa ar-Rasyidin dan Hasan Ibn Ali sangat berbeda dengan corak pemerintahan Daulah Umawiyyah dan setelahnya yang cenderung berbentuk kerajaan atau monarkhi. Bentuk kerajaan ini diperdebatkan apakah termasuk sistem Islami ataukah bukan. Kembali terjadi dualisme pendapat, yaitu yang mengatakan bahwa kerajaan adalah bagian dari pemerintahan Islam dan pihak yang menolak sistem kerajaan.

Terdapat hadits yang masyhur mengenai bentuk pemerintahan dalam Islam, yaitu bahwa Nabi Saw bersabda, "Khilafah setelahku berusia 30 tahun dan setelahnya adalah kerajaan” (As-Suyuthi, 1990:19). Hadits ini mengisyaratkan bahwa dalam Islam tidak terdapat bentuk pemerintahan khilafah yang baku, bisa berbentuk kekhalifahan sebagaimana dipraktekkan oleh Khulafaur Rasyidin dan bisa juga berbentuk kerajaan. Namun, pendapat lain, seperti Al-Baghawi, membantah hal tersebut. Ia bahkan secara tegas mengatakan bahwa kerajaan tidak termasuk dalam sistem pemerintahan Islam, bahkan disebutkan tidak sesuai dengan sunnah Nabi Saw (Al-Baghawi, 1983:75). Lagi-lagi, dengan adanya fakta ini, sistem khilafah Islam dengan sendirinya sangat dinamis, beragam, tidak tunggal, dan sangat multitafsir.

\section{E. Kesimpulan}

Sejarah telah membuktikan, penerapan khilafah di dunia Islam mengalami pasang-surut, pertumpahan darah di antara kaum Muslim sendiri tak terelakkan. Hal ini menunjukkan, sistem khilafah bukan satusatunya cara dalam mewujudkan nilai-nilai universal Islam. Perwujudan di setiap wilayah dapat menyesuaikan dengan corak dan karakteristik daerahnya, yang terpenting adalah nilai-nilai itu dapat tegak.

Sejarah dari perjalanan panjang khilafah Islam harus disikapi sebagai proses untuk mencari formulasi yang ideal mengenai konsep kepemimpinan di suatu negara/wilayah, yang boleh jadi pada 
penerapannya berbeda-beda. Satu hal yang patut dicermati adalah, sejarah seolah ingin mengatakan bahwa pelajaran yang terpenting dari sistem khilafah adalah pentingnya membuat sistem yang dapat saling mengkoreksi satu sama lain. Kekuasaan yang absolut cenderung berpotensi untuk disalahgunakan. Pertumpahan darah terjadi dalam sejarah kekhalifahan umumnya dikarenakan belum adanya sistem pengaturan mengenai sistem kontrol terhadap para khalifah jika umat tidak setuju dengan kebijakan khalifah. Terlebih lagi, umumnya masa jabatan khalifah adalah seumur hidup. Belum ada mekanisme dalam sistem khilafah yang mengatur mengenai berapa lama sesungguhnya seorang khalifah menjabat, apakah seumur hidup ataukah harus ada pengaturan mengenai batasan jabatan. Inilah sesungguhnya pekerjaan rumah yang perlu diselesaikan oleh umat Islam.

Sistem kepemimpinan dalam Islam masih harus terus digali dengan mempertimbangkan hal tersebut, yaitu dengan cara membangun sistem melalui kajian yang komprehensif mengenai sistem kontrol, pembagian kekuasaan, sistem distribusi ekonomi, sistem pengelolaan sumber daya alam, yang diambil dari khazanah kearifan Islam sehingga lebih dapat diterapkan dan sesuai dengan perkembangan tuntutan zaman.

Upaya menggali, mengkaji, dan merefleksikan berbagai kejadian dalam sejarah khilafah dalam upaya menggagas sistem khilafah dalam format baru tersebut sesungguhnya merupakan upaya untuk terus membumikan apa yang disampaikan dalam al-Qur'an bawa ajaran Islam adalah rahmatan lil 'alamin, bukan ajaran penebar teror seperti yang dituduhkan oleh banyak pihak yang merasa takut dengan penerapan sistem Islam. Formulasi yang perlu dicari adalah bagaimana nilai-nilai utama ajaran Islam dapat terwakili dalam sebuah sistem politik tanpa harus menimbulkan kecemasan bagi pihak lain dalam penerapannya. Sebaliknya, merupakan sistem alternatif baru yang dapat diterapkan di semua wilayah tanpa harus disebut sebagai negara Islam atau sebutan lainnya. 


\section{Daftar Pustaka}

Adz-Dzahabi, Siyar A'lam an-Nubala: Siyar al-Khulafa ar-Rasyidun. Beirut: Muassasah Ar-Risalah, 1996.

Al-Ya'qubi, Tarikh al-Ya'qubi, Beirut: Syirkah al-A'lamiy li al-Mathbu'at, 2010, Vol.II.

As-Suyuthi, Jalaluddin. Tarikh al-Khulafa, Saudi Arabia: Dar al-Minhaj li anNasyr wa at-Tauzi', Cetakan ke-2, 2013.

Asy-Syahrastani, Al-Milal wa An-Nihal, t.p., t.t.

Ath-Thabari, Tarikh ath-Thabari, Kairo-Mesir: Dar al-Ma'arif, t.t. Vol.III.

Baladzuri, Ansab al-Asyraf, Beirut: Dar al-Fikr, 1996, Vol.I.

Ibn Atsir, Al-Kamil fi at-Tarikh, Beirut: Dar al-Kitab al-'Arabiy, 2012, Vol.II.

Ibn Hisyam, As-Sirah an-Nabawiyyah, Beirut: Dar al-Kitab al-'Arabiy, 1990, Vol.IV

Ibn Khaldun, Tarikh ibn Khaldun, Beirut: Dar al-Fikr, 2000, Vol.II.

Ibn Qutaibah, Al-Imamah Wa as-Siyasah, Beirut: Dar al-Adhwa', 1990, Vol.I.

Imam Ahmad bin Hanbal, Kitab Fadhail ash-Shahabah, Mekkah Mukarramah: Dar Al-Ilmi li ath-Thiba'ah wa an-Nasyr, 1983, Cetakan I, Vol.I

Johny Ibrahim, Teori Metodologi Penelitian Hukum Normatif. Malang: Banyu Media, 2008.

Shahih Bukhari, Kitab al-Maghazi, Bab Mardh an-Nabiy Saw wa Wafatuhu, Vol.V,

Shahih Bukhari, Kitab Jizyah, bab Ikhraj al-Yahudi min Jazirah al-Arab, Vol.IV.

Shahih Muslim, Kitab al-Washiyyah.

Syaibah, Ibnu Abi. al-Mushannif, Beirut: Dar al-Kitab al-Ilmiyyah, 1992 , Vol.II. 